\section{The key}

The future's in your hands.

\section{Ian Whates}

It's amazing what a bunch of keys can say about a person. Key-rings and their contents hold hidden depths, or so Carl had always maintained.

Take his wife's, for example: keys for the front door, car, garage and a Yale for her mother's... plus various superfluous attachments: a pink plastic pig, a Perspex heart displaying the pseudo-word 'whateva', and a smiley-emblazoned disc designed to impersonate a coin when liberating supermarket trolleys.

His own set was far more practical. Keys for car and home, one for a suitcase and another for a young lady's flat that he trusted his wife would never notice or question. Two add-ons: a worn leather fob from his very first jalopy and a pizzle-shaped plait of woven leather that he'd been assured was a fertility symbol but probably wasn't.

Then there was the set he had recently 'acquired'. Six keys plus three attachments: a circular Mercedes emblem, matching one of the keys; a tiny plastic-encased photo of a girl's face - presumably the owner's daughter; and a small, squat figurine with blood-red crystal eyes. This last attachment vaguely resembled an owl and gave Carl the creeps. Quite what it said about the owner he preferred not to dwell on.

It was the keys that really intrigued him. Two differently cut front-door keys, suggesting two homes, Merc and Land Rover keys - a car for each dwelling - and two others less easily identified.

Sammy-the-Locksmith's considered opinion proved as much use as a chocolate teapot. "One's for a cabinet and the other a safety-depositbox."

"Any way of telling where it is?"

"Nope."

He wouldn't have cared, except for the small matter of the reward. A ridiculous sum, offered for the keys' return with no mention of the Gucci wallet lifted at the same time, nor of the cash and credit cards contained therein. One of these keys was clearly important to someone and therefore valuable. Carl knew which his money would ve been on. It remained useless to him, however, unless he could find precisely what it opened. To his growing frustration, unlocking that particular enigma proved beyond him.

"Mightn't even be in this country," his best and final hope had concluded with a shrug.
Reluctantly he arranged a meet, at a time and place of his choosing: a bar where he was known and felt safe. His recent victim and prospective benefactor awaited - a tall, muscle-broad individual who, even in an Armani suit, failed to look entirely polished or civilized. The rugged edges were still there: an uncut gem in a presentation box.

Carl would have preferred a dead-drop, an exchange without ever meeting faceto-face, but the other would have none of it. So he watched the man arrive from across the street, alert for any hint of police or other presence. Seeing none, he entered, glancing at the barman, whose shake of the head still fell short of total reassurance.

He took a deep breath and committed himself by sitting down. Eyes locked across a table. Unwavering self-confidence and steely strength couched within grey-blue irises, this was not a man to trifle with.

"You have the keys?" The voice was relaxed and casual to the point of being unnerving.

"You got the money?"

An envelope, produced from a pocket and then slid across the table. A fat envelope.

Carl reached out but the other's hand clung to its far edge. ${ }^{\alpha}$ The keys first.

"Not until I've counted it."

A frozen tableau that persisted for timestretching seconds until the man abruptly let go. Carl opened theenvelope and flicked through the wad of fifties, not counting with any accuracy, just checking.

Satisfied, he nodded to the barman, who left his station and came across with the keys.

To his credit, the stranger guffawed and nodded appreciation at such complicity. He looked the keys over once before pocketing them and rising to his feet. There he paused, fixing Carl with a glare - the first suggestion of either anger or menace.

¿Don't cross my path again."

"Just a minute," Carl blurted out as the man turned to leave. "You've got them back now, so you can tell me, why are they so important?

The man smiled - a malicious, satisfied expression, which lacked any hint of humour. “Do you really imagine I'm going to tell you?"

Carl watched the retreating back until it was out the door and away. Despite 